ESJ Social Sciences

\title{
Long-Term Care Regulations in Ontario, Canada during COVID-19
}

\author{
Steve Hunt, BSN, JD \\ Lakehead University, The Royal Ottawa Mental Health Centre, Canada \\ Elena Hunt, PhD \\ Professor Emeritus, Laurentian University, Canada
}

Doi:10.19044/esj.2021.v17n23p1

Submitted: 22 February 2021

Accepted: 02 July 2021

Published: 31 July 2021
Copyright 2021 Author(s)

Under Creative Commons BY-NC-ND

4.0 OPEN ACCESS

Cite As:

Hunt S. \& Hunt E. (2021). Long-Term Care Regulations in Ontario, Canada during COVID19. European Scientific Journal, ESJ, 17(23), 1. https://doi.org/10.19044/esj.2021.v17n23p1

\begin{abstract}
The Ontario, Canada statutory requirements of Nurse Patient ratios and other Health care professionals' activities are discussed following a descriptive, analytical and investigative approach. Using OECD Statistics and evaluating the impact on population health during COVID-19, as well as drawing from constitutional law and administrative law, the authors apply, explain and clarify opinions of jurists, rulings of judges and arbitrators and pull comparisons to statutory and statistical data from international jurisdictions such as Australia and USA. Recommendations for improvement of the Ontario Health Care system are conferred.
\end{abstract}

Keywords: Nurse Patient ratio, Covid-19, Long term care, Canada, Ontario, juridical analysis

\section{Introduction}

This article presents a critical look at the lack of regulation surrounding staff to patient ratios in hospitals and long-term care (LTC) homes in Ontario and Canada. While healthcare professions are highly regulated, there is little regulatory oversight in the provision of safe staff complements within hospitals and LTC facilities.

Specifically, this article reviews the lack of regulation mandating nurse-patient ratios with a particular emphasis on LTC homes. This topic is 
justified by an overwhelming body of research linking adequate nurse-patient ratios to a reduction in failure-to-rescue cases (FTR) (Aiken, Clarke, Cheunge et al., 2003), a reduction in the incidence of hospital-acquired infections (HAIs) (Cimiotti, Aiken, Sloane et al., 2012), a quicker recovery time and a reduction in the length of stay time (Carayon \& Gurses, 2008).

Mandatory nurse-client ratios have already been implemented in other jurisdictions, such as Australia and the USA with mixed results. One study cited by the Canadian Nurses Association articulated that there is currently no evidence on the effectiveness of legislated nurse-to-patient ratios, however, standardizing nurse-to-patient ratios would have both pros and cons (Hall, Lalonde, Murphy et al., 2019). Yet, despite this and according to the Organization for Economic Cooperation and Development (OECD), Canada's average places below other developed countries in areas such as rates of avoidable complications post-surgery and rates of foreign objects left behind after surgery (CIHI, 2019), indicators strongly linked to nursing-related interventions.

In a 2004 study, researchers compared international data on quality of medical care between 5 commonwealth countries, including Australia, Canada, New Zealand, England and the United States, and found that no one country scored the best or worst overall, but each country has an area in which it could learn from international experience (Hussey, Anderson, Osborn et al., 2004).

Ontario's current statutes and regulations governing hospitals and LTC homes are insufficient to address a consistent underperformance in key patient safety areas. To address the deficiencies in patient safety and improve patient outcomes, the legislator needs to consider mandating nurse-patient ratios within the province with a particular emphasis on LTC facilities.

\section{Nurse-Patient Ratios and Patient Outcomes}

Research has found a correlation between nurse education and patient outcomes. In one study, researchers found that a $10 \%$ increase in the proportion of nurses holding a bachelor's degree was associated with a 5\% decrease in both the likelihood of patients dying within 30 days of admission and the odds of failure to rescue (Aiken, Clarke, Cheunge et al., 2003). This is less relevant in Ontario as, since 2005, a bachelor's degree has been the minimum requirement for entry to practice as a registered nurse $(\mathrm{RN})(\mathrm{CNO}$, 2018). However, the registered practical nurses (RPNs) hold a two-year college diploma (CNO, 2020), and they frequently replace RNs.

Another study found that increasing the number of Registered Nurse working hours on a medical-surgical unit led to a reduction in the rate of patient falls and increases in reports of patient satisfaction with pain management (Sovie \& Jawad, 2001). In another study, a higher proportion of 
RNs to LPNs (the American equivalent of RPNs in Ontario) was associated with a shorter hospital stay, a lower rate of urinary tract infections, as well as a lower rate of upper gastrointestinal bleeding (Needleman, Buerhaus, Stewart \& Zelevinsky, 2002). Additionally, a higher proportion of RNs to LPNs correlated with lower rates of pneumonia, shock or cardiac arrest and lower rates of failure to rescue (Needleman et al., 2002). This reduction in failure to rescue was also observed in another study that found that a higher proportion of RNs to patients who have suffered an acute heart attack was less likely to die; however, they were statistically more likely to die in areas that had a higher ratio of LPNs to patients (Person, Allison, Kiefe et al., 2004).

Furthermore, research has found that a $10 \%$ increase in the proportion of RNs in all types of hospitals was associated with 5 fewer patient deaths for every 1,000 patients who were discharged (Tourangeau, Giovannetti, Tu \& Wood, 2002). Some research has even recognized a $45 \%$ reduction in emergency room repeat visits after discharge when $\mathrm{RN}$ presence per patient per day increased by 0.71 hours (Weiss, Yakusheva \& Bobay, 2011). Lastly, a systematic review of 26 studies found that decreased nurse staffing levels in intensive care units correlated to an increase in adverse patient outcomes such as mortality, infections, postoperative complications and unplanned extubation (removal of an intubation tube) (Penoyer, 2010).

\section{California's Approach to Nurse-Patient Ratios}

In 1999, former Governor Gray Davis signed Assembly Bill 394 into law which established minimum nurse-patient ratios for various hospital departments in California (McHugh, Kelly, Sloane \& Aiken, 2011). The purpose of this bill was two-fold, on the one hand, it was aimed to improve quality of care and patient safety and on the other hand, it was aimed to retain nurses in employment as, at the time, California was experiencing a massive nursing shortage (McHugh et al., 2011). The regulations specify different complements depending on the specialty area, for example in medical-surgical units it required, at first, 1 nurse to 6 patients, but after an 18 month grace period, required 1 nurse for 5 patients (McHugh et al., 2011). It wasn't until 2002 that the department of health announced its final ratios and the Bill went into full force and effect on January $1^{\text {st }}, 2004$ (McHugh et al., 2011).

While the passing of Bill 394 did not measure any improvement in patient safety among affected hospitals (Cook, Gaynor, Stephens \& Taylor, 2012) since the implementation of mandatory ratios, there have been better workload perceptions, increased job satisfaction, less burnout and significant reductions in workforce turnover (Serratt, 2013).

One of the reasons explaining this phenomenon may be that, before the implementation of the Bill, many hospitals already met the requirements specified by the Bill (Cook et al, 2012). Furthermore, the requirement for 
registration as a nurse in California, both LPN and RN, is an associate's degree (college level, non-baccalaureate) (Nightingale College, 2019). There is great diversity in who qualifies as a nurse in California and the level of training and education is quite variable when compared to the standards of Canada and Australia.

\section{Victoria, Australia's Approach to Nurse-Patient Ratios}

In Victoria, Australia, nurse ratios were traditionally bargained for through union and collective agreements (Australian Nursing \& Midwifery Federation, n.d.). These agreements generally allocated ratios of 20 patients to 5 nurses (or 1 nurse to 4 patients). However, in 2015, The Safe Patient Care (Nurse to Patient and Midwife to Patient Ratios) Bill was introduced (The Safe Patient Care Act, 2015). The goal of implementing this Bill was to ensure that both urban and rural hospitals operated at safe levels and that hospitals received the required funding for such complements (Australian Nursing \& Midwifery Federation, n.d.).

Since the implementation of safe patient ratios, Victoria has seen a $151 \%$ increase in patients receiving same-day treatment, hospital time reduced from $3.8 \%$ to $1.8 \%$, a $20 \%$ increase in urgent and semi-urgent elective surgery and Victorian hospitals work closer to capacity than any other Australian state (Australian Nursing \& Midwifery Federation, n.d.). Furthermore, Australia as a whole has seen a substantial decline in hospital sentinel events. Sentinel events are wholly preventable clinical incidents resulting in serious harm or death to patients (Australian Commission on Safety and Quality in Health Care, 2019). Between 2012 and 2014, Australia had rising sentinel events. Since 2014 onwards, the number of sentinel events has been decreasing dramatically and continues to decrease (Australian Commission on Safety and Quality in Health Care, 2019). Additionally, when compared to other Australian states, Victorian hospitals have the lowest cost in Australia and the lowest national length of stay average (Fitzpatrick, 2015).

Victoria has had positive outcomes following the implementation of Bill 2015. Another advantage of the Victorian over the Californian law is that it also applies to Aged Care Homes (LTC facilities in Ontario). The Bill requires 1 nurse +1 support worker for 7 residents in the morning, 1 nurse + 1 support worker for 8 residents in the afternoon and 1 staff (general, can be regulated or unregulated) for 15 residents during the night (Fitzpatrick, 2015). However, there is insufficient data comparing Victoria-specific Aged Care outcomes to the rest of Australia, thus the effects of these complements cannot be truly ascertained at this time.

In the proceeding section, a discussion of Canada's OECD indicators will be reviewed and compared internationally. 


\section{Canada's OECD Statistics}

Canada is one of the highest spenders in health care within the OECD nations network (CIHI, 2019). In 2018, Canada spent approximately $10.7 \%$ of its GDP on healthcare at a cost of roughly $\$ 6,448$ per adult person in the country (CIHI, 2019). This was similar to Australia who spent approximately $9.3 \%$ of their GDP or $\$ 6,488$ per adult person in the same year (CIHI, 2019). The highest spender was the United States, with healthcare comprising 16.9\% of their GDP at roughly $\$ 13,722$ per adult person in the country (CIHI, 2019).

Canada, as a country, performs poorly in trying to meet the OECD international average in patient safety indicators. It has done most abysmally in the rate of foreign bodies left in a surgical patient, with the international average being 3.8 per 100,000 people and Canada rating at 9.8 per 100,000 people, the highest of any other country. Another area where Canada has done badly is in obstetrical trauma. The OECD average is 5.5 per 100,000 people and Canada ranks at 16.4 per 100,000 people, again the highest of any other OECD country.

Furthermore, Canada shows the highest lengths of hospital stay, with an average of 7.5 days (between 2015 and 2019). In Australia, the average hospitalization stay is 4.1 days and in the USA it is 5.5 days (OECD, 2020). However, in terms of quality of care, Canada meets or exceeds the international average in more areas than it falls below average. For example, generally, survival rates for various cancer types exceed the international average (OECD, 2020). The only three areas that Canada falls below the international average are in avoidable COPD admissions, time spent with a physician and having a physician easy to understand (CHI, 2020A).

Canada underperforms in its LTC specific indicators. For example, in 2016, Canada counted 3.7 LTC workers per 100,000 people 65 years and older (OECD, 2020). By comparison, Australia reported 6.2 workers, while USA had 5.7. Furthermore, Canada's number of LTC workers has been declining, with the most recent count being 3.5 workers per 100,000 in 2018 (OECD, 2020). Canada's overall difficulty to supply LTC workers in accordance with the growing number of healthcare recipients is depicted in the chart below.

\section{Anatomy of Healthcare Mistakes in Canada}

Unfortunately, there is little data available about patient safety within LTC facilities, although Canada offers extensive information about patient safety within hospitals. According to the Canadian Institute for Health Information (CIHI) in collaboration with the Canadian Patient Safety Institute (CPSI), harm by medical errors is experienced by 1 in every 18 hospitalizations (Chan \& Cochrane, 2016). Most errors (56.6\%) happen on medical units in hospitals with $6.2 \%$ of patients experiencing harm (Chan \& Cochrane, 2016). Surgical units constitute the next area experiencing the most 
harm, with $19.8 \%$ of all incidents or $7.6 \%$ of patients suffering a harmful event. Further, $11.9 \%$ of incidents are suffered by newborns (1\% of patients) and $11.7 \%$ by obstetric patients ( $4.2 \%$ of patients) (Chan \& Cochrane, 2016). Most of the harmful events are either nursing related or mitigated by inadequate nursing ratios. For example, the most common harmful event comes in the form of healthcare-associated infections (37\%) and health care medication associated conditions (37\%) which include urinary tract infections (12\% of associated infections) and pneumonia (7\% of associated infections) (Chan \& Cochrane, 2016). Next come the procedure associated conditions (23\%), such as hemorrhage (7\% of harmful events) and lacerations or punctures (4\% of harmful events). The last category represents patient accidents such as trauma (related to falls or other incidents) which consist of $3 \%$ of events (Chan \& Cochrane, 2016).

Research shows that complex patients are at a higher risk of harm due to their comorbidities (multiple illnesses or complications) (Chan \& Cochrane, 2016). In addition, these complex patients are also more likely to experience more than one harmful event, particularly those ranking high in complexity being 3 to 4 times more likely to experience multiple occurrences of harmful events when contrasted to lower complexity patients (Chan \& Cochrane, 2016).

Tragically, one in 8 hospitalized patients who experience a harmful event will die (Chan \& Cochrane, 2016). However, a causal link that the harmful event was linked to the death cannot be established yet (Chan \& Cochrane, 2016), although an observable trend is worth noting. In fact, between 2014 and 2015, 12.5\% of patients who experienced at least one harmful event died in hospital (a total of 17,300 patients) which is significant as being 4 times the death rate of patients who do not experience a harmful event (Chan \& Cochrane, 2016).

Several prevalent and persistent safety issues were addressed in a comprehensive literature review of safety and quality in LTC homes, conducted in partnership with the CPSI (Wagner, 2008). One pivotal finding is a continuing and most frequently reported adverse event in LTC facilities, with a profoundly negative impact on residents (Wagner, 2008).

Another imperative issue in need to be addressed and identified in this study was the need for medication safety as there is a high prevalence of adverse events related to medication, among LTC residents (Wagner, 2008). Yet another pressing issue was healthcare-acquired infections which can be mitigated with the implementation of best practice guidelines and adherence to infection control practices (Wagner, 2008).

One important note to mention is that having zero errors, while ideal to strive for, is not realistic. Humans are not infallible, and errors are bound to happen. However, the statistics show that Canada has much room for 
improvement, especially when we consider its ranking against other OECD nations.

\section{The Current Legislation in Canada \\ Overview}

In Canada, healthcare is guaranteed to all Canadians under the Canada Health Act, 1985. The Act operates within the Constitution Act, 1867 of Canada to provide 'insured services' to all Canadians. Insured services are defined under section 1 of the Act as:

$[\mathrm{H}]$ ospital services, physician services and surgical-dental services provided to insured persons, but does not include any health services that a person is entitled to and eligible for under any other Act of Parliament or under any Act of the legislature of a province that relates to workers' or workmen's compensation (services de santé assurés).

Insured services represent what Canadians know to be the everyday healthcare they access, such as their appointments with physicians, their diagnostic tests or imagery scans. All of these are considered 'insured services' and thus covered under the Canada Health Act. Furthermore, the purpose of the Act is outlined in section 4 and stipulates the scope of the Act as:

Establish[ing] criteria and conditions in respect of insured health services and extended health care services provided under provincial law that must be met before a full cash contribution may be made.

The Act essentially lays the framework for healthcare in Canada, how resources are divided and the essential tenets of the Canadian healthcare system, namely Comprehensiveness, Universality, Portability, and Accessibility. The Act also makes provisions for billing and the allocation of Federal funds to the provinces for healthcare.

Despite the Canada Health Act, by the Constitution of Canada, the responsibility of the provision of healthcare falls to the provinces under section 92(7). Thus, each province has its array of statutes that direct, govern and regulate healthcare. This also extends to the regulation of LTC homes. The Canada Health Act is silent on the funding and allocation of services to LTC homes, this aspect being left to the respective provinces to manage and control (Government of Canada, 2005). Therefore, provinces are permitted wide discretion in regulating and managing the day-to-day activities, function, funding and control of such facilities.

Ontario, for example, implements a range of Acts, such as the Public Hospitals Act, the Health Insurance Act, the Medicine Act, the Nursing Act, the Health Protection and Promotion Act, the LTC Homes Act, and other various ancillary Acts. Each province has its Acts collectively working 
together to regulate and dictate the medical practices that the citizens of each province encounter in their day to day lives.

Notwithstanding the Canadian healthcare system being highly regulated and extensive in its scope, much of the day to day management of the healthcare institutions accessed daily by Canadians (such as hospitals and nursing homes) is left to the institutions themselves to develop and implement. For example, the Public Hospitals Act grants the broad authority of the management of hospitals to delegates. In particular, the hospital management regulations under the Act grants the hospital administrator the power to enforce the Act within the hospital and to provide for the overall management and direction of the hospital activities. While the Minister (of health) maintains control to enforce provisions of the Act, the ultimate day to day management of hospitals is bestowed to the administrator.

\section{Staffing Complement \& Structure}

Despite the regulations outlined in the health Acts of the provinces, currently, no single Act in Canada provides for the mandatory allocation of safe nursing or even staff complements. This means that the ascertainment of staffing complements in all healthcare institutions, be it hospitals, nursing homes and/or clinics is left to be determined by the administration of each respective institution.

Ontario has been criticized for failing to maintain an adequate number of healthcare professionals. For example, in 2018 there were only 690 Registered Nurses (RN) per 100,000 Ontarians (Ontario Nurses Association, 2019) and only 220 physicians for every 100,000 people (Bourgeault, 2018). However, generally, Canada's supply of nurses has been keeping up with its population growth. Between 2015 and 2019, Canada's supply of regulated nurses (including all nursing types: Registered Practical Nurses (RPN), RN and Nurse Practitioners (NP)) grew by $1.6 \%$, while population grew by $1.2 \%$ (CIHI, 2019B). However, the supply of RN grows slower than the supply of NP and RPN, by only $0.6 \%$ in 2018 (CIHI, 2019B).

This is significant, as the scope of practice between the various professionals varies depending on the designation. The scope of practice of each regulated nurse in Ontario is determined by a mixture of legislation and policy outlined by their regulatory body, the College of Nurses of Ontario. For example, the controlled acts that nurses may perform are outlined in the regulations under the Nursing Act and the Regulated Health Professions Act (RHPA). There are 14 controlled acts under the RHPA and generally, nurses are authorized to perform 5 of those acts (unless the nurse holds the designation of a nurse practitioner) (CNO, 2020B).

Generally speaking, nurses holding the $\mathrm{RN}$ designation are the ones who have the broadest scope of nursing practice and RPNs hold a more limited 
scope. Nurse practitioners (NPs) hold an enhanced scope, permitting them to prescribe medications, order diagnostic tests and practice in a role that is similar to that of a general practitioner; however, these nurses are not frequently employed in bedside hospital settings and their skills are used to bridge the gap for patients who require services that were traditionally only available through physicians.

The College of Nurses of Ontario provides guidelines on ascertaining which patients should receive care from an RPN vs an RN (CNO, 2018B). In their practice recommendations, they outline a three-factor framework for decision making about which nursing category should be used. This framework includes (CNO, 2018B):

1. Complexity: the greater the complexity (i.e. multiple illnesses, someone who is unstable medically, variable condition) the more likely the nurse should be of the RN designation (CNO, 2018B).

2. Predictability: the less predictable a patient's outcomes are and how a patient will fair, the more likely the nurse should be of the RN designation vs. a patient with predictable outcomes whose prognosis is relatively anticipated could be cared for by a nurse of the RPN designation (CNO, 2018B).

3. Risk of negative outcomes: the greater risk of a negative outcome related to a patient's condition, the more likely a patient will require a nurse of the RN designation (CNO, 2018B).

Some research has identified poorer outcomes in patients when the staffing mixed increased the number of RPN levels (Glance, Dick, Osler et al., 2012). The consensus in the research is that there is a direct link between RN staffing levels and patient outcomes. Despite this scientific results, the Acts in Ontario and Canada as a whole are silent on the allocation of skill mix within hospitals.

\section{The Failure of Legislation - Lessons learned from COVID-19}

Amid a worldwide pandemic, we are presented with an interesting opportunity to view the stability and strength of our healthcare system and its enabling regulations. Nothing can be starker than the noted failure of these regulations with respect to LTC facilities in Canada and particularly in Ontario.

As of December 2020, there have been over 3,000 COVID-19 related deaths in Ontario, with about $81 \%$ of these deaths occurring in LTC facilities (Grant, 2020). Furthermore, there have been more than 840 outbreaks in LTC homes and retirement homes (CIHI, 2020B). While Canada has relatively low COVID-19 mortality rates when compared to other OECD countries, Canada's LTC home-related deaths were higher at $81 \%$ than other OECD 
nations with an average of $38 \%$ of deaths (CIHI, 2020B). There is a significant difference between Canadian provinces, with no reported LTC homes deaths in Newfoundland and Labrador, Prince Edward Island and New Brunswick as of May $25^{\text {th }}, 2020$ whereas Quebec reports $70 \%$ of COVID-19 related deaths occurring in their nursing homes, Ontario $81 \%$ and Alberta 97\% (CIHI, 2020B).

Evidently, both Federal and Provincial Governments' lack of regulations and statutes addressing minimum safe nursing complements has directly contributed to the astronomical number of deaths of seniors residing in LTC facilities. This is even more apparent in the legislation regulating LTC homes in the province of Ontario, The LTC Homes Act. The Act sets the minimum standards of care and rules for the operations of a nursing home.

This is also the only Act that makes any mention of mandatory skill mixes and safe patient complements. Section 8(3) of this Act requires LTC facilities to employ at least one registered nurse who must always be on site, irrespective of the size of the nursing home, not the number of residents in it. This is extremely concerning as nursing homes can range from having as few as 20 residents to as much as 200 residents. The Act does not differentiate between nursing homes RN complement. Essentially, a home can have an infinite number of residents and, so much as they provide at least one registered nurse, they have met their obligations of "safe" nursing complements under the Act.

However, section $8(1)$ of the Act requires that a facility must ensure that there is:

(a) an organized program of nursing services for the home to meet the assessed needs of the residents; and

(b) an organized program of personal support services for the home to meet the assessed needs of the residents.

This highly subjective element of the Act has led facilities to employ situations that are highly unsafe for nurses and patients. The legislation is not only to blame for this, the funding scheme for LTC facilities is highly complex, relies extensively on documentation and generally is insufficient to meet the needs of the residents of the home (Ministry of Long Term Care, 2020). These conditions have impacted the labour supply for these homes, as staff attraction and retention continues to be a major issue for long term care homes (Ministry of Long Term Care, 2020). LTC homes continue to be put in a position where they must work with shortages of both regulated and unregulated care providers (Ministry of Long Term Care, 2020).

However, what is arguably even more concerning is that under section 45(1) of the general regulations of the Long-Term Care Homes Act, O Reg $79 / 10$, exceptions are made to which registered nurses may be allowed to not 
be on-site. For example, if a home has 64 or fewer beds, a registered nurse may be permitted to work from home in a situation where no registered nurse is available to be on-site and the regulations only require that they be available by telephone. If the home has between 64 beds and 129 beds, the same provision applies; however, with the addition that a registered practical nurse (RPN) must be available on-site at all times.

This becomes disturbing because even before the COVID-19 pandemic, long term care facilities in Ontario have been increasingly seeing an influx of residents with complex and difficult medical needs ( $\mathrm{Ng}$, Lane, Tanuseputo et al., 2020). In one Ontario based study, the researchers found that the proportion of individuals aged 85 and older increased from $45.1 \%$ to $53.8 \%$ in 2019 ( $\mathrm{Ng}$, Lane, Tanuseputo et al., 2020). The proportion of individuals with seven or more chronic conditions rose from $14.1 \%$ to $22.1 \%$ (Ng, Lane, Tanuseputo et al., 2020), and the proportion of those with 9 or more prescriptions rose from $44.9 \%$ to $64.2 \%$ (Ng, Lane, Tanuseputo et al., 2020). A final finding of this study was that residents who were newly admitted were more likely to have extensive physical and cognitive impairments on their admission into a care facility with at least five comorbid conditions, and one in five have at least seven or more comorbid conditions ( $\mathrm{Ng}$, Lane, Tanuseputo et al., 2020).

Despite patients with increasing clinical complexity falling within the scope of registered nurses, the legislation that enables LTC homes to operate does not reflect demand in their staffing mix. One Ontario based study concluded that the majority of direct care provided in long term care homes (76.5\%) was provided by unregulated care providers. However, this study also found an association between the number of care hours delivered to residents and the resident's quality of care. Furthermore, the quality of care was enhanced when care providers had attained at least seven or more years of experience (Boscort et al., 2018).

In a Ministry of LTC's staffing study of LTC facilities, it was noted a deficit of unregulated care providers or personal support workers (PSWs), shortage rampant across the province (Glance et al., 2012). In their conclusion, Boscort and colleagues (2018), state:

Associations between LTC staffing characteristics and overall quality of care were found for [PSW] care hours and [PSW] years of experience in the current LTC home. This study highlighted the importance of employing and retaining [PSW]s as they contribute to the quality of care in LTC homes.

However, the shortage of both regulated and unregulated care providers for LTC homes in Ontario has only amplified the crisis we have seen evolve amidst the COVID-19 pandemic and has served as a catalyst to augment an already tempestuous situation. The crisis has been so stark that Quebec had to request military personnel to assist in their LTC homes due to 
insufficient availability of staff (Aiello, 2020) and many homes in Ontario had to rely on healthcare professionals being donated from various healthcare institutions and hospitals from around the province (Artuso, 2020). This crisis shows that staffing practices employed by LTC homes have been unsustainable and insufficient to buffer against any type of external stressor. Interestingly, the deaths in LTC homes observed in other countries and even Canadian provinces reflect dramatic differences in the legislation of prescribed staffing. For example, Austria has seen roughly 19\% of COVID-19 deaths in their LTC homes (CIHI 2020). While some provincial variations apply in Austria, the minimum standard for LTC staffing is 1 full time equivalent (FTE) staff per 4 residents (on the high end) to 1 FTE per 1.9 residents (on the low end) (European Network of Economic Policy Research Institute, 2010). This is a far more robust mandate than any of the Canadian provincial statutes takes in provisioning staffing services within LTC homes. Australia had 28\% of their deaths happening in LTC homes (CIHI, 2020). However, Australia's Aged Care Act 1997 is vague and ambiguous about prescribing staffing levels within LTC homes (except for Victoria that has mandatory ratios). According to 41-3 of the Act, the stipulation is that homes are to provide: the person"

“...appropriate staffing to meet the nursing and personal care needs of

In a study done by the Australian Nursing and Midwifery Federation, it was found that, on average, a resident of an LTC facility in Australia received 2.84 hours of care/day by nurses, care workers and therapy staff. However, this was the average with 2.5 hours for the lowest and 5 hours for the highest (Australian Nursing \& Midwifery Federation, 2016).

In Ontario, as of 2018, each resident got an average of 2.3 personal care hours, 1.03 nursing hours and 0.4 allied health programming (Australian Nursing \& Midwifery Federation, 2016). This is similar to the Australian situation and thus, Australia's mitigation of COVID-19 deaths is likely attributable to their prompt response and implementation of pandemic plans (McKenna, 2020).

Quebec has seen the most deaths count from COVID-19 in LTC homes (CIHI, 2020), having also little to no provisions under their regulations and being completely silent on staffing provisions for private homes and public homes. However, way before COVID-19, Quebec's minister Marguerite Blais had announced that the government would assemble a committee of experts to draft a policy on LTC facilities. Yet, it is still unforeseeable as to whether or not this will be adopted into substantive law (Derfel, 2019) or how COVID19 will change this trajectory. 
Further in eastern Canada, in New Brunswick legislation, the regulations under the Nursing Homes Act NB Reg 85-187 section 18, stipulates:

An operator shall ensure that:

a) in nursing homes with thirty beds or more, the care of each resident is carried out by or under the supervision of a registered nurse as directed by the attending physician, or as directed by a nurse practitioner

b) in nursing homes with thirty beds or more, at least one registered nurse is on duty on the premises at all times,

c) in addition to the registered nurse referred to in paragraph (a), care staff is in attendance at all times in appropriate ratios, and

d) a comprehensive care plan is developed for each resident upon admission, reviewed at least annually and evaluated on an ongoing basis.

This regulation makes no exceptions to the rule of having the care provided to residents directed under the supervision of a registered nurse. However, the latitude allowed in Ontario and other provincial regulations has created a culture of blatant disregard for people's safety, injury and error prevention.

For example, in one labour arbitration case between the Ontario Nurses Association (ONA) and an LTC home, in one year the home had disregarded these regulations 11 times when they failed to have a registered nurse on-site in a home with 129 beds or more (Shepherd Village Inc v Ontario Nurses' Association, 2013 CanLII 31735 (ON LA)). What is also concerning is that, despite these breaches of statutes, LTC homes are not held accountable for their breach. In the same labour arbitration case, despite finding the LTC home in breach of the regulations, the arbitrator held:

The employer in this case had a 99\% compliance rate in 2012. With the same complement of nurses in 2013, it is quite possible it will be up to $100 \%$. There is thus no obligation on the employer to add more nurses. In the event of any further deficiency with the same complement, the union members would be entitled to compensation if one or more of them could point to a loss resulting from the deficiency, but, failing that, the only remedy would be a declaration that the employer had violated the agreement.

Essentially, the precedent that this arbitration case set is that it is okay to breach regulations sometimes, provided that most times you fulfill them. The fallacy of this presumption is demonstrated if we simply change the statute that was violated by the LTC homes Act to the Criminal Code. Would the arbitrator's argument raise questions of scrutiny if we were to say "it is okay that you committed 11 criminal acts because $99 \%$ of the time you weren't committing any criminal acts". It is shocking to see the latitude that is 
permitted with breaches of regulations that are intended to preserve the safety and integrity of a vulnerable population.

In another labour arbitration case between ONA and another LTC home, an issue arose with the home wishing to cut the hours staffed by registered nurses in a 166 bed, non-profit home (Kawartha Lakes (City) c Ontario Nurses' Association, 2015 CanLII 44015 (ON LA). While the parties were able to agree outside of arbitration on how to interpret this, the arbitrator had this to say, at para 13:

We have carefully reviewed and considered the parties submissions. In making our award to resolve the outstanding issues, we are guided by the legislative criteria set out in [Hospital Labour Disputes Arbitration Act, RSO 1990, c. H.14], which includes the following:

- The employer's ability to pay in light of its fiscal situation;

- The extent to which services may have to be reduced, in light of the decision or award, if current funding and taxation levels are not increased;

- The economic situation in Ontario and in the municipality where the employer is located;

- A comparison, as between the employees and other comparable employees in the public and private sectors, of the terms and conditions of employment and the nature of the work, performed;

- The employer's ability to attract and retain qualified employees.

This arbitration, in conjunction with a reading of the Hospital Labour Disputes Arbitration Act. RSO 1990, c.H.14 demonstrates a problem seemingly systemic in Ontario: a lack of willingness for the province to enforce safety within healthcare institutions. On one hand, Ontario attempts to provide for patient and healthcare safety with the enactment of regulations; however, on the other hand, Ontario has enacted regulations that permit exceptions to these safety requirements and has also enacted legislation that forces arbitration boards to give deference in light of fiscal and economic conditions. Essentially, Ontario chooses to underfund services, set unrealistic expectations and then permit these unrealistic expectations to be violated because it underfunds such services.

This is also apparent in the arbitration case of Westmount Long Term Care Residence v Ontario Nurses' Association [2016] OLAA No. 242, in which an LTC home intended to reduce RN hours owing to fiscal restraints. Westmount consisted of 3 LTC homes with greater than 120 beds in each of the homes. In this case, the LTC home anticipated a 3\% increase in funding from the Ministry of Health and LTC; however, they only received a $1 \%$ increase in funding. As a result of this shortfall in funding, the LTC home decided to reduce the weekly $\mathrm{RN}$ hours available to accommodate the 
budgetary shortfall. An interesting note of this case consists of the arbitrator's comments at para 156 - 157 when he writes:

Having regard to all the evidence, it is apparent that RNs are best equipped to provide the highest quality care to nursing home residents. RNs are the most qualified of the health care providers employed by nursing homes. The presence of an $\mathrm{RN}$ at a nursing home is essential for the safety and security of residents. This is because for the most part, nursing home residents are frail, vulnerable and constantly require various forms of care.

There is no doubt that frailness and vulnerability varies from resident to resident. It is also fair to say that stability also varies from resident to resident. Some residents have cognitive impairment issues, while others have physical impairment issues. Some residents have both cognitive and physical impairment issues. In all cases, the residents require some form of care and assistance from the various nursing staff.

The decision to remove RNs ultimately came as a result of the fact that the LTC home would need to cut either RN hours or PSW hours and a reduction of PSW hours would end up further impairing and reducing the number of direct care hours the residents of the home would receive. The ultimate justification came from the fact that there would be at least one RN available to consult with the RPNs available on site. Ultimately, this meant that one RN would be responsible for more than 120 residents, yet the arbitrator agreed to this in light of the fiscal restraints of the homes.

This disconnect cannot only be resolved at the legislative level, it needs to be resolved both legislatively and economically, with the more realistic appropriation of funds and resources to institutions to meet their legislative requirements.

\section{A Long-Standing Systemic Problem}

According to the Canadian Institute for Health Information (CIHI), it is estimated that the cost of healthcare was roughly $11.6 \%$ of Canada's GDP (CIHI, 2019D), about CAD 1.64-trillion in 2019 (Statista, 2020). That equates to approximately CAD 264-billion of healthcare spending (CIHI, 2019D). Of this, $27 \%$ of spending was attributed to hospitals, $15 \%$ to physician compensation and $15 \%$ to drugs (CIHI, 2019D). Of the hospital spending, $63.7 \%$ was spent on compensation of all staff (CIHI, 2020C). Further, of that $63.7 \%$, Nursing salaries accounted for $19.2 \%$ (CIHI, 2020C). This calculation would equate to nursing comprising 5\% of healthcare spending in Canada. Healthcare spending is highest on seniors, representing around $\$ 20,793$ for those age 80 and older (CIHI, 2020C). However, the ageing population only 'modestly' increases the healthcare expenditure at roughly $1 \%$ per year (CIHI, 2020C). However, the cost of paying physicians has exceeded growth in all other areas, at a $3.5 \%$ increase in cost vs $1.8 \%$ increase in drug expenses and 
$2 \%$ growth in the cost of hospitals (CIHI, 2019D). A breakdown of some of the costs Canadians spend on healthcare is summarized in the chart below. The data has been calculated based on available information from the Canadian Institute for Health Information (CIHI)'s healthcare spending report (CIHI, 2019D).

Repartition of Health Care cost by providers and incidents per person in Canada

\begin{tabular}{|l|l|l|l|}
\hline Cost & Total Cost & $\begin{array}{l}\text { Cost Per Canadian } \\
\text { Person }\end{array}$ & $\begin{array}{l}\text { \% of Healthcare } \\
\text { Spending }\end{array}$ \\
\hline Physicians & \$28.53 Billion & $\$ 758.98$ & $15 \%$ \\
\hline Nurses & \$13.2 Billion & $\$ 351.16$ & $5 \%$ \\
\hline Drugs & \$28.53 Billion & $\$ 758.98$ & $15 \%$ \\
\hline Residents in LTC & \$9.8 Billion & $\$ 260.71$ & $3.71 \%$ \\
\hline $\begin{array}{l}\text { Hospitals (excluding } \\
\text { nurse services) }\end{array}$ & \$58.1 Billion & $\$ 1,332.81$ & $22 \%$ \\
\hline Preventable Errors & \$685 Million & $\$ 18.22$ & $1 \%$ \\
\hline
\end{tabular}

Despite this cost and the growing cost considering inflation, the cost of physicians continues to increase with frequent raises in physician payments. For example, between 2018 and 2019, physicians were provided with a compensation increase of $1.25 \%$ on their billable services (Ministry of Health and Long-Term Care Ontario, 2020). As previously mentioned, the increase in the cost of physicians has exceeded inflation, namely by $3.5 \%$ (CIHI, 2019D). Furthermore, Ontario is not transparent about what physicians are billing the Ontario Health Insurance Plan (OHIP) and the allocation of funding to physicians (Draaisma, 2016). However, other provinces such as B.C. do list physicians' income/compensation/salaries. In one article by the Vancouver Sun, it was found that the national average of physician salaries in Canada was $\$ 338,605$ while the average in British Columbia was $\$ 279,986$ (Fayerman, 2016). The national average for physicians is just over 6 times the average provincial income in all of the provinces in Canada (Dodge, 2019). In the USA, according to the Medscape Physician Compensation Report, the national average salary of primary care physicians was USD 237,000 and it was USD 341,000 for specialists.

The issue with these rising Canadian salaries for physicians comes from the fact that physicians in Canada are remunerated based on billable services. When a patient meets a physician, each of the services is itemized and billed to the Ontario Health Insurance Plan. The structure of this plan is set out in both the Canada Health Act and the Ontario Health Insurance Act. The Ministry of Health and LTC for Ontario has a schedule of benefits that itemizes the cost of all the billable services physicians can charge based on the Ontario Health Insurance Act regulations (available here: 
http://www.health.gov.on.ca/en/pro/programs/ohip/sob/physserv/sob_master 20200306.pdf). For example, a non-emergency consultation in a hospital will cost the province approximately $\$ 167.35$. Consultation in a LTC facility will cost the province approximately $\$ 203.30$. While the policy statement outlines some requirements of consultation and ways to classify the complexity of a consultation, it is highly subjective. The regulations fail to specify why a consultation in an LTC home is worth $\$ 203.30$, yet a general consultation in a hospital is worth only $\$ 167.35$. This could create a potentially pathological incentive for physicians to work in more lucrative areas and extend themselves to provide services beyond what they can safely provide, creating an unbalaced situation of quantity over quality (Hewak \& Kovacs-Litman, 2015). The concern about this method of charging the province is only augmented by the lack of transparency in the billing. A patient in Ontario is never provided with an itemized bill of what their physician is charging the province. And should a patient ask for such information, they would be looked at in dismay, and ultimately have such requests denied. Hospitals are not equipped to provide patients with this basic information and, to the general public, why would they care?

But in fact, they should care, because physicians have a track record of 'over-billing' for services they either have not performed, did not adequately perform or had someone else perform (i.e. the nurse, nurse practitioner or physician assistant). There is no shortage of criminal (See e.g. $R v$ Gupta, 2007 CanLII 51705 (ON) and disciplinary action by way of the College of Physicians and Surgeons of Ontario (See e.g. Ontario (College of Physicians and Surgeons of Ontario) v Michael, 2020 ONCPSD 43 (CanLII)) in which physicians are found guilty of defrauding the Ontario Health Insurance Plan (OHIP). Furthermore, the province seems completely unprepared to handle these fraudulent claims as it takes, on average, 6 years before they are discovered. However, the province only has itself to blame. It has created a system that is, essentially, easy to defraud and permits physicians to shun accountability, while leaving the population in poor health despite its price tag.

Additionally, the regulations are illogical insomuch as they are formulated in a way that 'forgets' that nurses also provide care, while on salary, usually by the hour. For example, the guide says this about remuneration for intensive care patients (Ministry of Health and Long term Care Ontario, 2020B):

"Critical Care is the service rendered by a physician for providing, in an Intensive Care Area, all aspects of care of a critically ill patient excluding ventilatory support and includes initial consultation and assessment, emergency resuscitation, intravenous lines, cutdowns, intraosseous infusion, pressure infusion sets and pharmacological agents, insertion of arterial, C.V.P. 
or urinary catheters and nasogastric intubation with or without anesthesia, securing and interpretation of laboratory tests, oximetry, transcutaneous blood gases, and intracranial pressure monitoring interpretation and assessment when indicated (excluding insertion of I.C.P. measuring device). Except when a patient is on a ventilator, these fees are not payable for services rendered to stabilized patients in I.C.U.s, or patients admitted for ECG monitoring or observation alone. If the patient has been transferred from comprehensive care to critical care, the day of the transfer shall be deemed for payment purposes to be the second day of critical care."

The regulations permit physicians to charge $\$ 223.10$ for the first day and then $\$ 146.45$ per day, for these services for up to 30 days. After 30 days, the fee decreases to $\$ 58.60$ per day (Ministry of Health and Long term Care Ontario, 2020B). The problem is that many of these services are provided by critical care nurses. Many of the monitoring functions are performed by nurses and thus, a physician may only actually 'do something' once a nurse notices a deviation or change in the condition that requires a physician to intervene. This way, a physician can still charge for services they are not rendering. And the province is double-paying. They are paying the physician and they are paying the nurse to essentially do the same function.

If we are to combat the situation of 'double billing', fraudulent billing and arbitrary costs of services, we need to overhaul how physicians are remunerated. Instead of exhausting funds in the pursuit of physician remuneration, funds need to be allocated in a way that improves the capacity of the healthcare system as a whole and improves the safety of patients.

Ideally, the fee for service model employed by Canada would be completely abandoned. This model is not sustainable and, because of it consisting of $15 \%$ of our health spending, it is expensive. We need to allocate funds in a way that maximizes patient safety and quality improvement but is still equitable for those responsible for its delivery (i.e. physicians and/or nurses). To do this, we need to stop with variable payments and fee-for-service allocated to physicians and adopt a salaried approach. Research supports this approach, one study found that doctors operating under salary with less variability in their payment scheme were able to accept more complex patients, including Indigenous and patients from lower socioeconomic classes (Devlin \& Sarma, 2008). Research also shows that when the fee for services is abandoned and the rigidity of payment schemes loosened, physicians were more likely to spend more time with their patients (Dumont, Fortin, Jacquemet \& Shearer, 2008).

This problem is soundly discussed in an article by Grant and Hurley (2013) when they write in their executive summary:

Since 2000, the gap between what the average physician makes, and what the average fully employed Canadian worker earns, has diverged like 
never before. In the last decade, the average doctor went from earning threeand-a-half times the average Canadian worker's salary, to earning nearly fourand-a-half times as much, a more than 25 per cent relative increase. In constant dollars, today's average Canadian physician is earning about 30 per cent more than he or she was just a decade ago. All of this has occurred while physicians have actually provided slightly fewer services to patients.

The authors continue:

There are signs that this may have finally gone too far: Ontario was recently able to freeze remuneration for doctors in a negotiated contract deal and Alberta shortly after imposed a unilateral settlement on its doctors after breaking off negotiations. Stories about "millionaire doctors" are now proliferating in the mainstream media and, as provinces across the countries struggle with deficits, the public's sympathy appears to be shifting.

Physicians in the Canadian health-care system are entrusted with a special and protected role, and it behooves medical associations to bear in mind their additional responsibility to promote public health-care objectives. The current collective bargaining model has resulted in provinces pressured into buying healthcare peace by agreeing to continually ratchet up doctors' pay. It is difficult to see how that can continue. It is time that doctors began working with policy-makers on a new model, one that puts less emphasis on profiting doctors, and more emphasis on promoting a sustainable health-care system for everyone.

There has been a general and unsubstantiated fear that even so much as looking at the salaries of physicians skeptically will suddenly lead to a nation-wide exodus of physicians to the USA, as we have seen in the 90 s when the government decreased medical school seats by 10\% (Belluz, 2012). However, this fear is just not based on evidence. The supply of physicians is currently at an all-time high in Canada (Belluz, 2012) and the USA is not in a position to accept, or even need, a massive surplus of Canadian trained physicians. But what can happen if we continue to stack the deck in favour of physicians, is see a massive exodus of the very disciplines that are giving up their half of the pie in favour of physicians. Those being nurses and other ancillary and allied healthcare professionals. This has already been the case for nurses in the 90s and, even today, we continue to see a great number of nurses going to the USA. In fact, in 2003 there were approximately 5,366 Canadian RNs that were working internationally, with $81.5 \%$ of those, working in the USA (Little, 2007).

Furthermore, this favouring of medicine over other professions and over improving the quality of care, in general, is not translating into quality care, as we have seen from Canada's OECD statistics. Other countries that take a more equitable approach to physician remuneration (such as Australia and even the USA) outperform Canada in many indicators. Furthermore, the 
fact that Canada falls below the international average in almost all safety indicators in and of itself is telling.

Let's be clear and without advocating towards cutting physician compensation. Equity in remuneration based on skill, experience, education, professional attainment and remuneration based on performance (this area is where we are lacking as a country), is generally foundational to capitalist societies, of which Canada is one. Thus, physicians should rightly be paid what they are worth in the grand scheme of things and how they perform (based on quality indicators, perhaps related to the health of our population). One does not need to reinvent the wheel; one simply needs to adopt the policies and remuneration styles that prove successful in other countries.

Currently, Canada operates more of an autocratic style healthcare system (with ultimate control granted to the government) that works inequitably to favour the elites (physicians) at the expense of not only other disciplines but also at the expense of Canadian citizens (both in terms of the taxes they pay and the value they receive). Restructuring physician compensation and healthcare control to be more like in Europe, Australia and even the USA seems to have, at least in research studies, an ability to improve quality outcomes for patients. But the overarching goal that needs to be accomplished is a reduction in the spending burden to allocate funding to other areas that need it more, such as in the provision of medical and nursing services to those in LTC homes. Healthcare needs to be viewed as a service rather than a business or a for-profit undertaking.

\section{Conclusion}

Long term care in Canada and healthcare needs a reset. The current model of spending and regulating is unsustainable. With healthcare in Ontario alone costing more than $\$ 60$-billion, the current modus operandi of, at the very least, Ontario's healthcare sector is unsustainable. Comparisons with other countries' healthcare systems are useful and may help in redesigning our own. It is insufficient to take a bottom-up approach in this situation. It is not sufficient to place the burden on the LTC facilities and healthcare institutions to reform themselves in a way that will enhance patient safety. Rather, this change needs to start from the top by amending the very legislation that has enabled their existence within the province.

The provincial government needs to mandate safe nursing complements within Ontario. They also need to overhaul their funding scheme in a manner that permits LTC facilities to meet such safe staffing requirements. It borders on negligence for the province to allow exceptions within their legislation that permit LTC facilities to operate in conditions that are completely unsafe and inadequate to meet the needs of the community it 
serves. In the face of COVID-19, the provinces' failure and inadequacy has been broadcasted for all the world to see.

While the government has attempted to evade liability for any harm it inflicts by its policy decisions during COVID-19 (see e.g. Bill 218 Supporting Ontario's Recovery and Municipal Elections Act, 2020), harm that has been caused to residents of LTC homes in Ontario is not a result of the government's COVID-19 policy decisions. These provisions have been in force long before COVID-19 and have been jeopardizing the safety of LTC residents for years. However, it took a pandemic for the world to finally see the fragility and vulnerability of this house of cards the province has built for its seniors.

\section{References:}

1. Aiello, R., (April 17, 2020) Canadian military to help in Quebec LTC facilities online:

https://www.ctvnews.ca/health/coronavirus/canadian-military-tohelp-in-quebec-long-term-care-facilities-1.4901019

2. Aiken, H. L., Clarke, P.S., Cheung, B. R., Sloane, M.D., \& Silber, H.J. "Educational levels of hospital nurses and surgical patient mortality", (2003) 290:12 Journal of the American Medical Association

3. Artuso, A., (April 17, 2020) All hands on deck to help LTC homes. Online:

https://torontosun.com/news/provincial/all-hands-on-deck-to-helplong-term-care-homes

4. Australian Commission on Safety and Quality in Health Care, (2019)

The State of Patient Safety and Quality in Australian Hospitals 2019. Online:

https://www.safetyandquality.gov.au/sites/default/files/2019-07/thestate-of-patient-safety-and-quality-in-australian-hospitals-2019.pdf at 21.

5. Australian Nursing \& Midwifery Federation, Nurse/Midwife Patient Ratios, (n.d.) online:

https://www.anmfvic.asn.au/ /media/f06f12244fbb4522af619e1d530 $4 \mathrm{~d} 71 \mathrm{~d}$

6. Australian Nursing \& Midwifery Federation, National Aged Care Staffing and Skills Mix Project Report (2016) online:

http://www.anmf.org.au/documents/reports/National_Aged_Care_Sta ffing_Skills_Mix_Project_Report_2016.pdf p 8 .

7. Belluz, J. (September 14, 2012) Are we in for another doctor exous to the U.S.? (September 14, 2012) online: 
https://www.macleans.ca/society/health/are-we-in-for-anotherdoctor-exodus-to-the-u-s/

8. Bourgeault, I., (2018) Ontario likely has enough doctors. Online: https://www.thestar.com/opinion/contributors/2018/05/22/ontariolikely-has-enough-doctors-if-we-make-better-use-of-other-healthworkers.html?rf

9. Boscort, V. et al., (2018) The associations between staffing hours and quality of care indicators in LTC. 18:750 BMC Health Services Research.

10. Canadian Institute for Health Information (CIHI), Canada's patient safety performance below OECD average (November 7, 2019), online: https://www.cihi.ca/en/canadas-patient-safety-performancebelow-oecd- average.

11. Canadian Institute for Health Information, How does Canada's health spending compare? (2019) online:

https://www.cihi.ca/en/how-does-canadas-health-spendingcompare\#: :text=Canada\%20is\%20among\%20the\%20highest,the $\% 2$ 0United $\% 20$ States $\% 2 \mathrm{C} \% 20$ at $\% 20 \% 2413 \% 2 \mathrm{C} 722$.

12. Canadian Institute for Health Information [CIHI], OECD Interactive Tool: International Comparisons - Health Status (2020A) online: https://www.cihi.ca/en/oecd-interactive-tool-internationalcomparisons-health-status

13. Canadian Institute for Health Information (CIHI), (2019B) Canada's patient safety performance below OECD average, online:

https://www.cihi.ca/en/canadas-patient-safety-performance-belowoecd-average.

14. Canadian Institute for Health Information, Nursing in Canada: A Lens on Supply and Workface (2019B) online:

https://www.cihi.ca/sites/default/files/document/nursing-report-2019en-web.pdf $\mathrm{p} 10$.

15. College of Nurses of Ontario, Entry-to-Practice Competencies for Registered Nurses (2018) online:

https://www.cno.org/globalassets/docs/reg/41037-entry-to-practicecompetencies-2020.pdf at 3

16. College of Nurses of Ontario, Entry-to-Practice Competencies for Registered Practical Nurses (2020A) online:

https://www.cno.org/globalassets/docs/reg/41042_entrypracrpn2020.pdf at 3.

17. Canadian Institute for Health Information, Nursing in Canada: A Lens on Supply and Workface (2019C) online:

https://www.cihi.ca/sites/default/files/document/nursing-report-2019en-web.pdf p 10.col 
18. Canadian Institute for Health Information, Pandemic Experience in the LTC Sector (June 2020B) online: https://www.cihi.ca/sites/default/files/document/covid-19-rapidresponse-long-term-care-snapshot-en.pdf $\mathrm{p} 1$.

19. Canadian Institute for Health Information [CIHI], Health spending in Canada reaches $\$ 264$ billion (October 31, 2019C) online:

https://www.cihi.ca/en/health-spending-in-canada-reaches-264billion\#: :text=National $\% 20$ health $\% 20$ expenditure $\% 20$ by $\% 20$ the $\% 2$ 0numbers\&text=It $\% 20$ is $\% 20$ estimated $\% 20$ that $\% 20$ health, $\% 25) \% 20 \mathrm{a}$ nd\%20physicians\%20(15\%25).

20. Canadian Institute for Health Information, What are hospitals spending on (June 18, 2020C) online:

https://www.cihi.ca/en/what-are-hospitals-spending-on

21. Canadian Institute for Health Information [CIHI], National Health Expenditure Trends, 1975 to 2019. Ottawa, ON: CIHI; 2019D p 16

22. Chan, B \& Cochrane, D. (2016) Measuring Patient Harm in Canadian Hospitals. With What can be done to improve patient safety? Canadian Institute for Health Information at $\mathrm{p} 17$

23. Cimiotti, J., Aiken, L., Sloane, D., Wu, D., "Nurse staffing, burnout, and health care-associated infection", (2012) 40:6 American Journal of Infection Control (USA: Agency for Healthcare Research and Qualtiy (US), 2008) ch. 30.

24. College of Nurses of Ontario, Legislation and Regulation: RHPA: Scope of Practice, Controlled Acts Model (2020B) online: https://www.cno.org/globalassets/docs/policy/41052_rhpascope.pdf p $3-4$.

25. College of Nurses of Ontario, $R N$ and RPN Practice: The Client, the Nurse and the Environment (2018B) online:

https://www.cno.org/globalassets/docs/prac/41062.pdf

26. Cook, A., Gaynor, M., Stephens, M., \& Taylor, L., (2012) The effect of a hospital nurse staffing mandate on patient health outcomes: Evidence from California's minimum staffing regulation. 31:2 Journal of Health Economics at 340.

27. Derfel, A. (September 20, 2019) Quebec to draft new policy on LTC. Online: https://montrealgazette.com/news/local-news/quebec-todraft-new-policy-on-long-term-care

28. Devlin, RA., Sarma, S. (2008) Do physician remuneration schemes matter? The case of Canadian family physicians, 27:5 Journal of Health Economics.

29. Dodge, M. (June 20, 2019). The Average Canadian Salary in 2019, online: 
https://www.jobillico.com/blog/en/average-canadian-salary/

30. Draaisma, M. (April 02, 2016) Ontario Sunshine List: Why aren't doctors on it? online:

https://www.cbc.ca/news/canada/toronto/doctors-billing-1.3516578.

31. Dumont E, Fortin B, Jacquemet N \& Shearer B. (2008) Physicians' multitasking and incentives: empirical evidence from a natural experiment. 27:6 Journal of Health Economics.

32. European Network of Economic Policy Research Institute, (May 2010) The Austrian LTC System. Online:

https://www.files.ethz.ch/isn/122381/Austria.pdf p 33.

33. Fayerman, P. (December 9, 2016) Medicine Matters: What your doctor earns - the latest Blue Book on fees. Online:

https://vancouversun.com/news/staff-blogs/medicine-matters-whatyour-doctor-earns-the-latest- blue-book-onfees\#: :text=BC\%20doctors $\% 20$ make $\% 20$ less $\% 20$ than,to $\% 20 \mathrm{BC} \% 2$ 0doctors\%20were\%20\%24279\%2C986.

34. Fitzpatrick, L., (2015) The Victorian Nurse and Midwife Patient Ratios the Road to Legislation. online: http://www.worldpsi.org/sites/default/files/attachment/news/lisa_fitzpatrick.pdf

35. Glance, L., Dick, A., Osler, T., Mukamel, D., Li, Y. \& Stone, P. (2012) The Association between nurse staffing and hospital outcomes in injured patients. 247 BMHC Health Services Research.

36. Government of Canada (October 1, 2005), Long-term facilities-based care, online: https://www.canada.ca/en/health-canada/services/homecontinuing-care/long-term-facilities-based-care.html

37. Grant, H. \& Hurley, J. (2013) Unhealthy Pressure: How Physician Pay Demands Put the Squeeze on Provincial Health-Care Budgets. 6:22 University of Calgary School of Public Policy at $\mathrm{p} 1$.

38. Grant, K. (June 25, 2020). $81 \%$ of COVID-19 deaths in Canada were in LTC - nearly double OECD average. Online:

https://www.theglobeandmail.com/canada/article-new-data-showcanada-ranks-among-worlds- worst-for-ltc-deaths/

39. Hussey, P., Anderson, G., Osborn, R., Feek, C., McLaughlin, V., Millar, J., \& Epstein, A., (2004) How Does the Quality of Care Compare in Five Countries? 23:3 Health Affairs.

40. Little, L. (2007) Nurse Migration: A Canadian Case Study. 32:3 Health Services Research at 1345.

41. McGillis Hall, L., Pink, M., Lalonde, G., Tomblin Murphy, L., O'Brien-palla, H., Laschinger et al. "Decision Making for Nurse Staffing: Canadian Perspectives" (in press) Policy, Politics and Nursing Practice. 
42. McGillis Hall, L., Doran, D. \& Pink, G.H. (2004) Nursing staffing mix models, nursing hours and patient safety outcomes, 34:1 Journal of Nursing Administration at 44.

43. McHugh, M., Kelly, L., Sloane, D. \& Aiken, L (2011). Contradicting Fears, California's Nurse-To-Patient Mandate Did Not Reduce The Skill Level of The Nursing Workforce in Hospitals. 30:7 Health Affairs at 1299.

44. McKenna, T. (June 13, 2020). Australia's COVID-19 successes shine a light on Canada's troubled LTC sector. Online:

https://www.cbc.ca/news/world/australia-covid-19-long-term-care1.5591912

45. Hewak, M. \& Kovacs-Litman, A. (2015) Physician compensation structures and how they incentivize specific patient care behaviour. 84:1 University of Western Ontario Medical Journal at 15.

46. Ministry of Health and LTC Ontario (March 31, 2020A), Ontario Health Insurance Plan OHIP Bulletins. Online:

http://www.health.gov.on.ca/en/pro/programs/ohip/bulletins/4000/bul 4751.aspx\#: :text=Year\%202\%20(2018\%E2\%80\%932019)\%20of\% 20the $\% 20$ Award $\% 20$ provides $\% 20$ for,for $\% 20$ Year\%202\%20is\%202. $0094 \% 25$.

47. Ministry of Health and LTC Ontario, Physician Services Under the Health Insurance Act (March 19, 2020B) online: http://www.health.gov.on.ca/en/pro/programs/ohip/sob/physserv/sob master20200306.pdf

48. Ministry of Long-Term Care, (2020) LTC Staffing Study online: https://files.ontario.ca/mltc-long-term-care-staffing- study-en-202007-31.pdf p 3.

49. Needleman, P., Buerhaus, S., Mattke, M., Stewart, K., Zelevinsky. (2002) Nurse-staffing levels and the quality of care in hospitals. 346:22 New England Journal of Medicine at p 1718-1721

50. Ng R, Lane N, Tanuseputro P, Mojaverian N and colleagues, (2020) Increasing complexity of new nursing home residents in Ontario, Canada: a serial cross-sectional study. 68:6 Journal of the American Geriatrics Society.

51. Nightingale College, (October 25, 2019) Will a BSN degree be mandatory for RNs? online: https://nightingale.edu/blog/rn-bsnrequirements-by-state/

52. OECD (2020), Health Status (2020) online: stats.oecd.org

53. Ontario Nurses Association (2019) Last again - Ontario has the most dismal $R N$-to-population ratio in the country.

Online:

https://www.newswire.ca/news-releases/last-again-ontario-has-themost-dismal-rn-to-population-ratio-in-the-country- 
54. Papaioannou, A. et al., (2018) Building Capacity in LTC: Supporting Homes to Provide Intravenous Therapy (2018) 21:4 Canadian Geriatrics Journal.

55. Penoyer, D. (2010) Nurse Staffing and patient outcomes in critical care: a concise review. 38:7 Critical Care Medicine

56. Person, S. D., Allison, J. J., Kiefe, C. I., Weaver, M. T., Williams, O. D., Centor, M. R., \& Weissman, N. W., (2004) Nurse staffing and mortality for medicare patients with acute myocardial infarction. 42:1 Medical care at $\mathrm{p} 4-12$.

57. Serratt, T. (2013) California's Nurse-to-Patient Ratios, Part: 8 Years Later, What Do We Know About Nurse-Level Outcome? 43:9 Journal of Nursing Administration at 478.

58. Sovie, M. D ., Jawad, A. F. (2001) Hospital restructuring and its impact on outcomes: Nursing staff regulations are premature. 31:12 Journal of Advance Nursing at 589.

59. Statista, (February 2020) Real gross domestic product (GDP) of Canada from 2000 to 2019. Online:

https://www.statista.com/statistics/650869/real-gdp-

canada/\#: :text=In\%202019\%2C\%20the\%20real\%20GDP,dollars\%2 0at\%202012\%20constant\%20prices.

60. Tourangeau, A. E., Giovannetti, P., Tu, J. \& Wood, M. (2002) Nursing-related determinants of 30-day mortality for hospitalized patients. 33:4 Canadian Journal of Nursing Research at 71-88.

61. Wagner, L. (2008) Safety in LTC Settings: Broadening the Patient Safety Agenda to Include LTC Services. Canadian Patient Safety Institute.

62. Weiss, M., Yakusheva, O. \& Bobay, K. (2011) Quality and Cost Analysis of Nurse Staffing, Discharge Preparation, and Postdischarge Utilization. 46:5 Health Services Research. 